the South African Chats, to some of which Mr. Seebohm has applied his principle of hybridisation, as we are not yet satisfied that the changes of plumage cannot be accounted for by the more natural process due to age or the season of the year. These few remarks will not, however, detract from the sterling merit of Mr. Seebohm's volume, which bears on every page the evidences of the careful and exhaustive work which the author bestows on every subject he handles. The eighteen coloured plates are beautiful examples of Mr. Keuleman's great talents as a natural history artist, and the colouring is much more satisfactory than in the last volume of this Catalogue, issued by the British Museum.

\section{MAGNETIC AND AURORAL OBSERVATIONS} IN HIGH LATITUDES ${ }^{1}$

IEUTENANT WEYPRECHT, the noted leader of L. the Austrian Arctic Expedition of $1872-74$, whose death is a great loss to science, recently published a little text-book embodying the results of his wide experience in Arctic observation of magnetic and auroral phenomena, which will be invaluable in pointing out to future observers the precautions and requirements which only actual experience of Arctic life can suggest, and the arrangements of apparatus and stores, which, once left behind, must be done without ; frequently to the loss of opportunities for observation which do not recur. It would however be wearisome to the general reader to enter into details of Arctic work, and no one to whom the matter is of practical moment will omit reading the book itself. Some however of the precautions suggested give so vivid an idea of the difficulties and even the suffering which Arctic observers have to meet in the cause of science, that we cannot forbear a passing mention of them.

In magnetic observatories, where iron is rigidly tabooed, and uniformity of temperature is of the first importance, stoves are naturally out of the question. In winter, when the huts are thickly covered with snow, the temperature should never fall below $-20^{\circ} \mathrm{C}$. $\left(-4^{\circ} \mathrm{F}\right.$.), which, as Weyprecht says, may be borne for some hours in suitable clothing without severe suffering. Good fur garments are naturally essential. The most difficult part is the sufficient protection of the feet, that found most effectual being very wide felt boots reaching to the knee, into which the feet, clad in thick woollen stockings, are packed with dry hay or straw. The hands are covered with thick woollen gloves, and whenever they are not in actual use are further protected by fur. In absolute determinations however, which have to be carried on in a separate hut, which is also used as an astronomical observatory, and hence more open to the weather, the cold is not only much more intense, but the fingers must be left bare, or at most covered with thin cotton gloves, on account of the delicacy of the instruments. On two occasions during the Tegetthoff Expedition such quantities of snow were driven into the observatory through the crevices of the shutters as, by loading one side of the telescope, actually to throw it off its pillar.

For absolute magnetic observations Weyprecht gives preference to Prof. Lamont's portable theodolite, which contains in itself everything necessary for the determination of declination and horizontal and vertical intensity. If however a fixed scale could be attached to the telescope for rapid readings the instrument would be still further improved.

With regard to northern light observations, Weyprecht repeats his important classification of auroral forms given in his Nordlichtbeobachtungen. For observations on the altitude of auroræ, with a view to calculation of height, he recommends a simple instrument consisting of a tube with an eye-piece, movable in the magnetic meridian, and

x " Praktische Anleitung zur Beobachtung der Polarlichter und der mag etischen Erscheinungen in hohen Breiten," vun Carl Weyprecht, Schiffs
eutenant. (Wien, 188r.) with an altitude circle reading to $\frac{1}{2}^{\circ}$. The tube must be attached to the end of the axis, so as to be capable of sweeping the entire meridian. The observations should be repeated at short and regular intervals, and both the upper and lower edges of the arches should be observed, thus giving at once the mean altitude and the breadth of the bands. If the "dark segment" is visible, its mean height and the azimuth of its summit must be observed, as it probably indicates the direction of the origin of the aurora. If a corona is formed the approximate position of its centre must be observed. Another method of determining the position of the corona is by measuring the direction of the rays of which the arches are formed. This is best done by measuring their inclination from the perpendicular in two azimuths $90^{\circ}$ apart. If the tube we have mentioned be provided with an azimuth circle and cross-wires in the eye-piece with a position circle reading to $\frac{1}{2}^{\circ}$ this is readily accomplished, the perpendicular being verified by observation of a plumb-line.

For spectral observations Weyprecht considers directvision instruments of good dispersion the most suitable In low latitudes we have found a single bisulphide prism and simple slit and eye-hole without lenses to answer well, and if such an instrument were attached to the same axis as the measuring tube, which would act as a finder, we believe it would show fainter spectra than any direct vision arrangement. We do not know however how it would be affected by Arctic temperatures. Weyprecht does not mention any means of measuring the position of the lines-the simplest is Piazzi Smyth's comparison with the hydrocarbon spectrum of a spirit-lamp, and another very good scale is the band-spectrum of air yielded by a vacuum-tube fixed across the slit and made to flash as required.

Weyprecht insists on the importance of further comparisons between the movements of the aurora and magnetic disturbances, and points out the high interest that would also attach to observations of the earth-currents.

H. R. PROCTER

\section{NOTTINGHAM UNIVERSITY COLLEGE}

THE fine building, auspiciously opened the other day as a college in the heart of Nottingham, represents the last development of that all too tardy interest in higher education which, in the more recent years, has originated the Victoria University in Manchester, the Yorkshire College in Leeds, the Science College in Newcastle (a flourishing offshoot of Durham University), the Mason Science College in Birmingham, and others.

It is gratifying to find in a new provincial centre, with its varied activities and the usual temptations associated with money-getting, an intelligent, if somewhat late, appreciation of the thirst after knowledge for its own sake, as well as for that to which it may be profitably applied, and a disposition to take generous means of satisfying it.

Of the inception and growth of the Institution we need not here speak at any length. The elements of a college were already in existence. For seven or eight years past lecturers from Cambridge have visited Nottingham and drawn large audiences. The Government Science Classes were also highly appreciated. It is thus estimated that no fewer than 1400 students will be ready to take advantage of the instruction soon to be provided. Nottingham, moreover, has possessed a public library since 1868, and this, along with the Natural History Museum, greatly needed larger accommodation. From the union and consolidation of these and other educational agencies under one roof where the conditions of progress are much more favourable, excellent results may be anticipated. A distinctive feature of the Nottingham College is that it has been built by the Municipal 
Corporation of the place, is to be held as corporate property, and will be sustained mainly out of the corporate funds. With a total cost of $70,000 l$. (or, taking into account the value of the land, 100,000l.) the only endowments at present are the $10,000 \%$ presented by an anonymous donor, and $300 \mathrm{l}$. from Lady Ossington (for a scholarship). It is expected that the trustees of the late Mr. F. C. Cooper will, in accordance with his will, apply some part of his estate towards the endowment of classes in the College, but it is not at present known how much. Thus the expense of maintenance will, at least in the outset, mainly fall on the town itself. The experiment will doubtless be watched with interest.

The general internal arrangement of the new building may be here briefly noticed. The library-rooms are in the eastern wing, to the left of the principal front, and the natural history museum is housed in the other wing. The former include two reading-rooms on the ground and first floors. Behind the principal entrance are placed the three theatres for chemical, physical, and general lectures, the two former having laboratories, work-rooms, and professors' rooms attached. The largest theatre accommodates 600 persons, the chemical 220 , and the physical 100. These rooms are well provided with modern appliances. In addition may be noted a balance-room, and an optical gallery I 25 feet long for experiments in light.

It is stated in the report of the Organisation Committee that all persons will be admitted students who give evidence of their desire to improve their education and make advances in the acquisition of knowledge. More particularly the object of the founders of the institution seems to have been of a threefold character. First of all the College will absorb, as already indicated, the University Extension Lectures and Classes and the Government Science Classes, developing and systematising the courses of instruction in which these have been engaged. Next a technological school will be provided, and classes formed for teaching, in a more direct manner, the theoretical parts of certain trades. Once more, the preparation of students for residence at the older universities seems to have been contemplated ; but this feature will probably, at least for some time, have little prominence.

For the purpose of systematic education the course of instruction has been arranged under four heads: (I) ancient and modern languages, literature, history, political philosophy and economy, logic, and philosophy; (2) mathematics, theoretical and applied mechanics, and physics; (3) inorganic and organic chemistry, pure and applied; (4) biological science, botany, zoology, and physiology; also geology and allied subjects. In the Government Science Classes (distinct from the College curriculum) instruction will be given in several of the subjects in which aid is given by the department at South Kensington. The Technological School will deal with the following among other subjects:-Cloth, cotton, silk, lace, and hosiery manufactures, weaving, metallurgy, gas manufacture, telegraphy, pottery and porcelain, bleaching, dyeing, and printing, tanning, mechanical engineering, oils, colours, and varnishes. It is to be distinctly understood, however, "that these classes are not so much for teaching trades as for teaching those subjects which underlie work and bear upon trade, and help to develop the intellect of the workmen."

The scheme of education provided will thus be seen to be of a comprehensive nature. All who are solicitous that England should take a good place among the nations in industrial competition will be glad to see a new technical school added to the few we already possess. The number of these schools will have to be greatly multiplied before we have anything like the advantages of Germany in this respect. In this connection we may direct attention to an interesting little volume recently written by $\mathrm{Mr}$. Felkin (a native of Nottingham, by the way) who has carried on the manufacture of hosiery in Chemnitz, Saxony, since 186I, and describes what is being there done in the way of technical instruction, and its results. (Mr. Samuelson criticises the system in the Fortnightly this month.) The aspects of such technical education are various, and not the least in importance is that the workman, who is thereby enabled to feel an intelligent interest in his work, to comprehend the scientific principles on which it is based and the conditions of excelling in it, and to seek to do it as well as he possibly can, becomes conscious of mental growth and expansion. He even thus acquires new vistas (to use Prince Leopold's expression), and finds the drudgery of routine materially light. ened. For those again who seek culture in different directions (scientific or literary) from that bearing on their daily work, a wide range of subjects is presented for choice. The cultivators of science for its own sake will doubtless not be wanting, and some excellent solid work, we trust, will be done. The youth seeking to be trained for a scientific career, and the working lad ardently pursuing some favourite study in his scanty hours of leisure, may alike resort to the College for stimulus and direction.

In the strong reaction which has become evident in recent years from that neglect of science which was so long prevalent among us, it has appeared to some that there is now an objectionable tendency to onesidedness in education. However this may be, the founders of the new College have determined, and we think wisely, that it should be more than merely a college of science and technical institute, and the purely literary elements of culture are included.

The requirements of the industrial population will be respected by the holding of classes in the evening, and the adoption of lighter fees than those for the daystudents. The teaching will be conducted by resident professors, non-resident lecturers, and local teachers; and the student, after passing through the regular course of instruction and training, will, on passing an examination, receive a certificate.

The four professors required for the curriculum have been appointed as follows:-Professor of Language and Literature, Rev. J. E. Symes, M.A. ; Professor of Mathematics and Mechanics, Dr. J. A. Fleming, B.A.; Professor of Chemistry, Dr. F. Clowes, F.C.S. ; Professor of the Biological Sciences, Rev. J. F. Blake, M.A. One of the professors will act as Principal or Dean, with some extra emolument.

The University College of Nottingham, in fine, begins its career with good promise of usefulness, and it is to be hoped that wealthy and liberal friends of education will respond in a practical way to the appeal of the College Committee, who "desire it to be known that they are prepared to receive endowments in aid of the funds of the College." We hope soon to hear that the burden of maintenance for the townspeople has been thus happily diminished.

\section{ANTHROPOLOGY ${ }^{1}$}

$\mathrm{TO}$ those readers whose knowledge of ethnology or anthropology has been derived from a perusal of Prichard's " Natural History of Man," or the compilations of Wood, Brown, Peschel, or Brace, the present work will present a surprising amount of freshness and originality. They will in fact find themselves introduced to a new and very captivating science. Instead of the disconnected, and often confusing accounts of the numerous races, families, and tribes into which mankind have been divided, with separate details of the appearance, manners, customs, houses, implements, weapons, and ornaments of each, the reader of the present work will be shown how I "Anthropology: an Introduction to the Study of Man and Civiliation, by Edward B. Tylor, D.C.L., F.R.S. With Illustrations. (Lond ws: Mac millan and Co., 188x.) 